Xiaoqin Yin

Chenchen Dong

Chuang Liu

DOI: $10.21278 /$ TOF.41108

ISSN 1333-1124

eISSN 1849-1391

\title{
GLOBAL VALUE CHAIN RESTRUCTURING IN THE TRADE OF KNOCKED DOWN PRODUCTS
}

\begin{abstract}
Summary
Trade in knocked down products embodies the international division of labour and the distribution characteristics of the global value chains. The value chain of the trade in knocked down products is defined in this paper through the analysis of the process of the intra-product international division of labour. Firstly, the value chain of knocked down products is divided into two parts, i.e. the value chain of product design and production and the value change of product assembly and sale. Then, the necessary conditions are deduced to realize the reconstruction of the value chain. The tariff escalation policy of the importing country is the main reason for the disruption of the product value chain and the value shifting to the importing country. Finally, the areas of value chain disruption in the cases of various modes of trade in knocked down products are established. As a result, the research on the restructuring of the value chain in the trade in knocked down products will help companies choose a high value link in the value chain from the global distribution perspective.
\end{abstract}

Key words: $\quad$ value chain reconstruction, global value chain, trade in knocked down products, intra-product division, tariff escalation

\section{Introduction}

Trade in knocked down products refers to a mode of international trade in which the last assembly procedure of the production process is transported to another country. It also has the form of international manufacturing. The target objects of the trade in knocked down products are complex products with high added value that are to be assembled, such as motor bikes, automobiles and engineering equipment. The multinational transfer of the follow-up procedures helps to achieve the outward expansion, which is favorable for the industrial development of an importing country. The importing country drafts various types of tariffs based on the extent to which the value chain extends to the importing country in the process of trading in knocked down products. The tariff escalation policy of the trade in knocked down products is a stimulating measure to build a value chain of knocked down products to extend largely into the country of origin from the perspective of the importing country's government. This kind of stimulating measures has been applied by more and more emerging 
markets. Concerning the global value chain, the majority of the trade in knocked down cars in China is downstream the product chain. This means that China enters the value chain of the trade in knocked down products during the stage of assembling imported knocked down products and the production of accessories. On the other hand, the trade in knocked down motor bikes in China is at the highest stage of the exportation of knocked down products. As a result, research on the restructuring of the value chain in the trade in knocked down products will help companies with choosing the link with a high value in the value chain from the global distribution perspective.

\section{The reconstruction of global value chain}

Porter's [1] value chain is commonly regarded as the traditional value chain that intends to analyze the value activities of a corporation and the possible links between corporations and suppliers or customers, and the competitive advantages gained from them. The value chain theory by Kogut [2] has led to the global value chain theory research. He argues that a specific form of an international business strategy is actually the final result of the interaction between the comparative advantage of a country and a corporation's competitive ability. The national comparative advantage is decisive in the spatial allocation of the whole value chain links in different countries and areas, and a corporation's competitive ability determines which technological level or link a corporation should focus on to maintain its competitive advantage. Contrary to Porter's concentration on the value chain of a single corporation concerning the competitive advantage, Kogut [2] proposes his view which will better reflect the relations between the vertical departure of the value chain and the reallocation of global space, which is of assistance to the understanding of the working mechanism of the in-product international working division. Gereffi [3] and other scholars proposed an analytical framework of Global Commodity Chain and made a direct linkage between the concept of value chain and global organizations. In the background of economic globalization, the manufacturing process is disintegrated into different stages. With the production of a specific product, a multinational manufacturing organization system comes into being, and the global value chain takes shape by integrating corporations and organizations with different scales into a systematic network.

Therefore, the global value chain is formed with the disintegration and extension of value space. The collective manufacturing form of a single kind of product begins to be replaced by the division of different manufacturing links in a product. The following intraproduct international division is developed inside different procedures and flows of the global value chain. The formation and development of the global value chain provides foundation for the intra-product international division, whereas the mechanism of vertical control, management and drive brought from the functioning of the global value chain provides safety for the internal coordinative functioning of the intra-product international division network.

Some researchers have been working on the fragmentation and spatial reconstruction in the value chain. Krugman discussed a corporation's ability to allocate all the value chain links in different geographic spaces [4]. As a result, the relation between the governing model and transfer of an industrial space becomes an important research area of the global value chain theory. Arndt and Kierzkowski describe the splitting phenomenon in the manufacturing process as Fragmentation. The links of a manufacturing process in the same value chain are organized through the multinational manufacturing network, which could be done by a corporation internally or different corporations. The disintegration of property is an important decisive factor of multinational production organizations. Multinationals and foreign direct 
investments will be the first choice if the disintegration of property cannot be implemented. If it is applicable, consignment manufacturing will be adopted, and foreign direct investment will not play an important role [5]. Some Chinese scholars have also conducted some research in this field. Chen Feiqiong and Wang Danxia have studied the dynamic property of the global value chain in the perspective of corporation upgrade [6]. Yi Meiqun has proposed the term "deconstruction" to represent the phenomena of disintegration and reconstruction with the analysis of the definition of value [7]. These research results of value chain and global value chain lay a theoretical foundation for the value chain reconstruction of the trade in knocked down products.

\section{Global value chain of trade in knocked down products}

The trade in knocked down products belongs to the intra-product international trade. A number of investigations into the intra-product international division as a form of division of labour have been conducted in the field of economics. The research on the value chain reconstruction of the trade in knocked down products in this paper belongs to the field of management. The international division of labour is developed from cross-industry division to intra-industry division, then to intra-product division which is developed into intra-product trade $[8,9]$. The trade in knocked down products is intra-product division which belongs to intra-product trade. According to the definition of the trade in knocked down products, the division of knocked down products includes the division stages of manufacturing and assembly. The former one is the exportation of knocked down products, and the latter is the importation of knocked down products. As can be seen in Figure 1, division stages of the trade in knocked down products are divided on the basis of production and manufacturing defined by the intra-product trade. But these division ranges, including the Research and Development $(\mathrm{R} \& \mathrm{D})$ stage and the sales stage in the importing country, belong to processing trade, service trade, and technology trade. Consequently, the trade in knocked down products belongs to the intra-product trade from the point of view of trade forms. However, according to the value added section of the value chain, it is necessary to do an analysis by extending the division ranges to the whole value chain. The exporter in the trade in knocked down products is on the prevailing side.

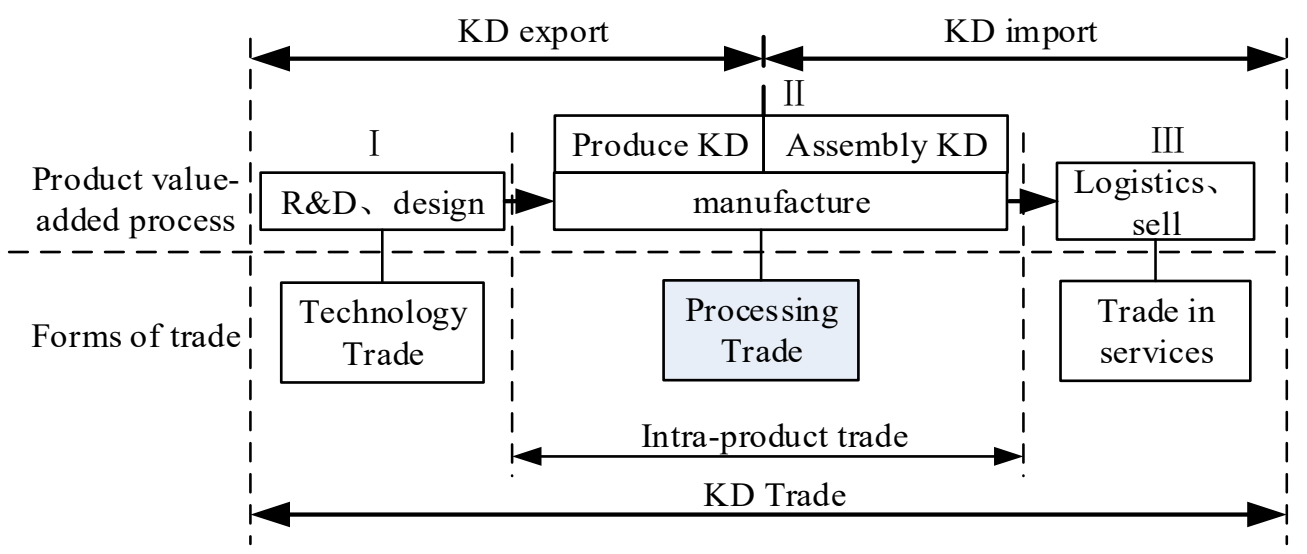

Fig. 1 Analysis of trade in knocked down products

Exporter conducts the research, design and manufacturing of knocked down products having an advantage in research, organization and manufacturing areas to promote and uphold the exportation of knocked down products. The packaging process of a knocked-down product is done by the exporter as an after-production activity. Product research and 
production of knocked down products are upstream the product manufacturing and the packaging and selling of knocked down products are downstream. In a word, the value chain of the trade in knocked down products is a combination of research and design, manufacturing of knocked down products, international trade, packaging of knocked down products, logistics and sales section. Manufacturing of knocked down products has great ability to add value as it is closely related to technical research. Manufacturing downstream has little ability to add value for it is hardly related to technical research.

\section{Disruption of value chain and reconstruction conditions}

Before complex assembly products are produced, the value chain reflecting the entire value-added process when products are exported to importing countries is showed in the upper part of Figure 2. The Value V in the whole chain consists of Chains A1 and A2 within the corporation, Chain B during the exporting process (the main factor blocking this chain being the tariffs of importing countries) and Chain $\mathrm{C}$ in the product sale in importing countries.

$$
V=A 1+A 2+B+C
$$

The disruption process of the value chain of the trade in knocked down products is reconstructed in the lower part of the chain in Figure 2, in which the assembling process A2 is disintegrated from the value chain within the corporation and inserted into the stage prior to the product sale in importing countries. The products turn from integrated to knocked down products through the reconstruction and the value in the trading stage transfers from B to B'. The value in the trading stage is mainly affected by the tariff change.

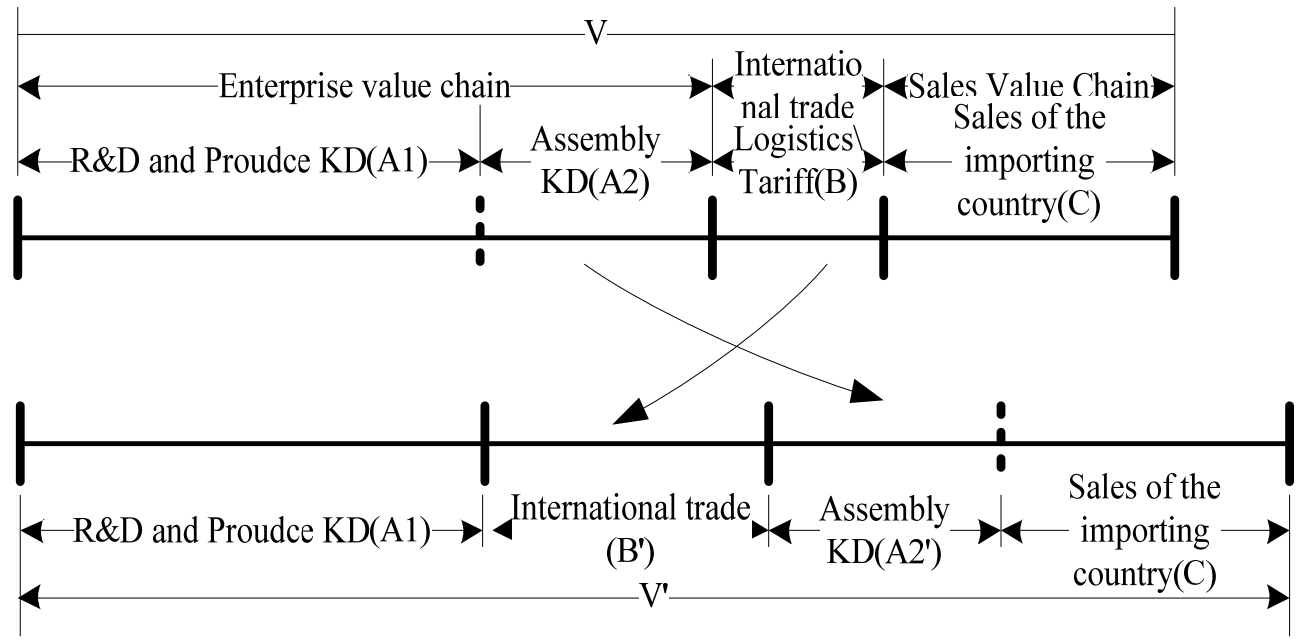

Fig. 2 Disruption and reconstruction of the value chain of trade in knocked down products

As the assembling stage A2 is transferred to the importing countries, due to different factor pricing and different levels of technology, the value will change from value A2 of the assembling stage of knocked down products within the corporation to A2'. Let the reconstructed total value of the chain be $\mathrm{V}^{\prime}$. If the chain is rebuilt within the corporation, in other words, the corporation assembles and sells the products in the importing countries by foreign direct investment, and the conditions of the trade in knocked down products chosen by the exporting corporation (conditions to achieve the trade in knocked down products) will be value added in the whole value chain. Such a case can be considered as trade in knocked down products within corporation. If knocked down products are sold to other companies in importing countries, the condition to achieve the trade in knocked down products will be that 
the value of the chain section reserved by corporations should be greater than the whole value of the original chain. This case is considered as the inter-corporation trade in knocked down products. (2) expresses conditions that have to be fulfilled to achieve inter-corporation and intra-corporation trade in knocked down products, respectively:

$$
\begin{aligned}
& \begin{cases}A 1+B^{\prime}>V & \text { inter-corporation } \\
V^{\prime}>V & \text { intra-corporation }\end{cases} \\
& V^{\prime}=A 1+A 2^{\prime}+B^{\prime}+C \\
& \begin{cases}B^{\prime}>A 2+B+C & \text { inter-corporation } \\
A 2^{\prime}+B^{\prime}>A 2+B & \text { intra-corporation }\end{cases}
\end{aligned}
$$

If the tariffs on knocked down products and the integrity products are equal $\left(B=B^{\prime}\right)$, the value chain restructuring condition becomes:

$$
\begin{cases}0>A 2+C & \text { inter - corporation } \\ A 2^{\prime}>A 2 & \text { inter - corporation }\end{cases}
$$

Clearly, the condition of the inter-corporation trade in knocked down products in formula (5) is unsatisfied, which means that the international division of labour in the intercorporation trade in knocked down products will not emerge without implementing tariff escalation policies. However, the corporation trade in knocked down products in (5) is established. In economic studies concerning intra-product division, the corporation trade in knocked down products especially refers to foreign direct investments that are prompted by a case where the countries importing knocked down products have a comparative advantage over the countries exporting knocked down products. Due to the complexity of the products for the trade in knocked down products, the assembly of knocked down products also requires high technology and professional equipment. Such advantage will not be seen in the beginning of the trade in knocked down products and it does not mainly cause the disruption of the value chain.

Analyzing different links of the chain in the division of labour in the trade in knocked down products, it is found that a critical mass of the division of labour is driven by some "center link" which encounters the barriers. The core of the "centre link" is the tariff escalation policy. Product division is actually a process of making the ladder type tariff in form of trade cost distributed to each link of the production, during which the "value chain" will continue to "crack" with the step variation of the tariff and the "product manufacturing process" splits into the process of production of knocked down products and the process of assembling knocked down products.

Let the value variation based on the tariff change during the stage of international trade be $\Delta B, \Delta B=B^{\prime}-B . \Delta B$ is caused by the tariff escalation policies. The trade in knocked down products gets less integrity as the tariff lowers, and the added value in the stage of trade will be higher. So (4) can be changed as follows:

$$
\begin{cases}\Delta B>A 2+C & \text { inter - corporation } \\ \Delta B>A 2-A 2^{\prime} & \text { intra - corporation }\end{cases}
$$


According to the conditions of the inter-corporation trade in knocked down products in (6), the tariff difference between complete products and knocked down products ought to be large enough to achieve the inter-corporation trade in knocked down products. In terms of the conditions for the corporation trade in knocked down products, though importing countries do not possess a comparative advantage or even their factors of products are inferior to those of exporting counterparties, the value chain will still crack and the values will be transferred to the importer if the tariff escalation is structured properly so that the importing tariff can be adequately reduced to counteract the disadvantage of the domestic factors of production. Without considering the comparative advantage, the motivation to achieve the corporation trade in knocked down products is:

$$
B^{\prime}>B
$$

Therefore, the trade in knocked down products is mainly motivated by tariff escalation policies. From the structure of the tariff escalation in the trade in knocked down products, the larger the tariff difference between complete products and knocked down products is, the more easily the value chain will break.

The position where the value chain breaks also closely relates to the tariff structure. The splitting line between the process of production of knocked down products and the process of assembling knocked down products determines different degrees of the value transference. The hatched section of Figure 3 shows the areas where the value chain breaks.

Due to the complexity of the products, usually there is no internationally unified criterion to clearly define the boundary line between the division of labour in the production of knocked down products and the assembly of knocked down products. In order to home the value chain to their own countries, importers often establish several different forms of assembling knocked down products within vague boundaries, through which a stretch region is derived from the division of labour in the trade in knocked down products and it results in various models of knocked down products. As Table 1 shows, in international trade, the export of products as complete units is called a complete product exporting model and the value chain is to the right side of the production and manufacturing stage in Figure 3. As exports increase, importing countries gradually strengthen the trade protection by implementing tariff escalation and matching the imports of knocked down products to a lower tariff rate. According to different levels of the value transfer, forms of knocked down products are divided into four types and each of them will be taxed differently.

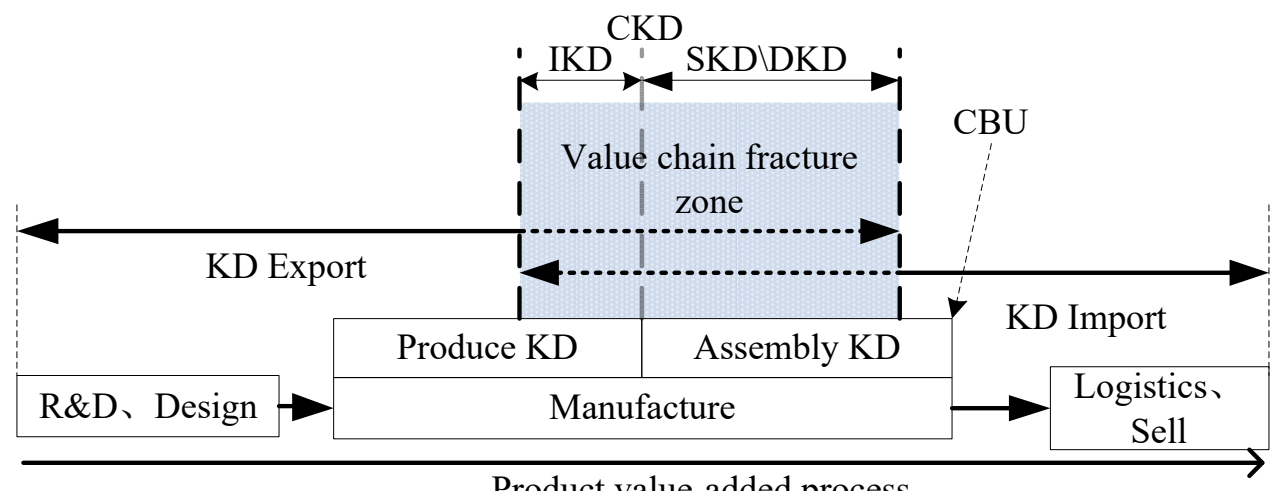

Product value-added process

Fig. 3 The fracture zone in the value chain of trade in knocked down products 
Table 1 Comparison of physical structure states

\begin{tabular}{c|c|c}
\hline Export forms & Simple & Tariff \\
\hline Completely Built Up & CBU & Very High \\
Direct Knocked Down & DKD & Very High \\
Semi Knocked Down & SKD & Higher \\
Completely Knocked Down & CKD & Low \\
Incompletely Knocked Down & IKD & Lowest \\
\hline
\end{tabular}

For instance, the import tariff for a Vietnamese motorbike IKD is 5\% to $15 \%$; for CKD and $\mathrm{CBU}$ it is $60 \%$ and $100 \%$, respectively; for an Indonesian motorbike IKD is $5 \%$ to $10 \%$ and $\mathrm{CKD}$ is $25 \%$; for $\mathrm{CBU}$ whose displacement is under $250 \mathrm{ML}$ it is $60 \%$; for an African Beninese IKD is $0.2 \%$ and CKD and SKD is $5 \%$, respectively. The import tariff taxed on a Chinese finished automobile is $25 \%$ and generally, the tariff for components is about $10 \%$.

Obviously, when the tariff difference is bigger, the point of disruption of the value chain is more towards the left side, and more value is shifted to the import country (Figure 3 ). Certainly, according to equation (6), the point of disruption of the value chain should be adjusted so that the value chain can be optimized in terms of superiority and tariff escalation.

\section{Conclusion}

Trade in knocked down products belongs to intra-product trade considering the form of trade. The intra-product trade is built on the international division of labour which exists in the area of production and manufacture. The trade in knocked down products also divides the labour in such areas and particularly takes the production and assembly of knocked down products as the line of demarcation. However, taking the value chain into consideration, the trade in knocked down products achieves a more specific division than the intra-product trade. It is reflected in the processing trade, service trade and technology trade. The division of labour also involves research and development and marketing of knocked down products in importing countries. Therefore, the value chain of knocked down products includes product development and design, production of knocked down products, international trade, assembly of knocked down products, logistics and sales. Initial motivation is facilitated by the tariff escalation in importing countries, which breaks the chain and makes it constantly restructured completing the value transfer. When the value appreciation in the trade stage is sufficient to offset comparative disadvantages of importers, the corporation trade can be achieved while the inter-corporation trade in knocked down products is going to be realized as the value appreciation in the trade stage is larger than the value of the assembly and sales of knocked down products in importing countries. Specific forms of the trade in knocked down products usually include DKD, SKD, CKD and IKD. Further quantitative research on the relationship between the cascading tariffs and the trade in knocked down products would be helpful for the formulation of the tariff policy.

\section{REFERENCES}

[1] Porter M, Competitive Advantage: Creating and sustaining Superior Performance, New York: The Free Press, 1985; (1), 356-384.

[2] Kogut B, Designing Global Strategies: Comparative and Competitive Value-added Chains, Sloan Management Review, 1985; (4), 26-27.

[3] Gefeffi G, A Commodity Chains Framework for Analyzing Global Industries, Working Paper for IDS, 1999; (1), 320-329. 
[4] Krugman P, Growing World Trade, Brookings Papers on Economic Activity, 1995; (1), 32-52.

[5] Amdt S. and Kierzkowski H. Fragmentation, New Production Patterns in the World Economy, Oxford University Press, 2001; (2), 256-278.

[6] Chen Feiqiong and Wang Danxia, The dynamics of global value chain and upgrading of enterprises, Science Research Management, 2007; 28, 52-59.

[7] Yin Mei-qun, An analysis on value chain and its deconstruction, Science Research Management, 2006; 27, 153-155.

[8] Feng Lu, Intra-product Specialization, China Economic Quarterly, 2004; (4), 55-82.

[9] ZHAO Zheng-jia, Quantity Discount and Its Combined Contract for Global Supply Chain under Uncertain and Price- Dependent Demand, Journal of Industrial Engineering and Engineering Management,2015; 29(3),90-99.

$\begin{array}{ll}\text { Submitted: } & 17.4 .2016 \\ \text { Accepted: } & 14.12 .2016\end{array}$

Assoc. Prof. Xiaoqin Yin (corresponding author, xqyin@cqu.edu.cn, +08618523578093) Chenchen Dong College of Mechanical Engineering, Chongqing University, Chongqing, China Assist. Prof. Chuang Liu Chengdu Vocational \& Technical College of Industry, Chengdu, China 